\title{
A European lightning density analysis using 5 years of ATDnet data
}

\author{
G. Anderson and D. Klugmann \\ Met Office, FitzRoy Road, Exeter, EX1 2HR, UK \\ Correspondence to: G. Anderson (graeme.anderson@metoffice.gov.uk) \\ Received: 27 August 2013 - Published in Nat. Hazards Earth Syst. Sci. Discuss.: 4 December 2013 \\ Revised: 2 November 2013 - Accepted: 21 February 2014 - Published: 11 April 2014
}

\begin{abstract}
The Met Office has operated a very low frequency (VLF) lightning location network since 1987. The long-range capabilities of this network, referred to in its current form as ATDnet, allow for relatively continuous detection efficiency across Europe with only a limited number of sensors. The wide coverage and continuous data obtained by Arrival Time Differing NETwork (ATDnet) are here used to create data sets of lightning density across Europe. Results of annual and monthly detected lightning density using data from 2008-2012 are presented, along with more detailed analysis of statistics and features of interest. No adjustment has been made to the data for regional variations in detection efficiency.
\end{abstract}

\section{Introduction}

The use of lightning location systems (LLS) across Europe and the wider world for operational meteorology and research purposes is well established. Lightning data are used daily for observing the development and progression of storms, and also in research projects (such as the HyMeX (Hydrological Cycle in the Mediterranean Experiment) project, Ducrocq (2013)) in order to gain a better understanding of the processes taking place within storms.

Most European countries operate a lightning location system. The majority use relatively dense networks of low frequency (LF, 30-300 kHz)/very high frequency (VHF, 30$300 \mathrm{MHz}$ ) sensors to detect the "sferic" (radio atmospheric) signals emitted by lightning. These types of network provide high detection efficiency (DE) and location accuracy (LA), but are generally limited in range outside of the area enclosed by the network of sensors. However, the current use of sensors primarily from a single provider allows for crossborder coverage via cooperation within organisations such as EUCLID (European Cooperation for Lightning Detection) (Schulz and Diendorfer, 2002). The LINET (Lightning detection Network) VLF (very low frequency, 3-30 kHz)/LF LLS, developed at the University of Munich and operated by nowcast, is also capable of providing extensive coverage of much of central Europe (Betz et al., 2009).

An alternative approach to lightning detection is to detect sferics using a much lower frequency range, i.e. the very low frequency range, in which radio signals propagate over the horizon in the waveguide created by the Earth and ionosphere, in order to create a "long-range" network. Only a small number of such long-range networks exist at the time of writing, including the University of Washington WWLLN (Worldwide Lightning Location Network) system (Jacobson et al., 2006), the Vaisala GLD360 (Global Lightning Dataset 360) system (Said et al., 2010), the National Observatory of Athens ZEUS network (Lagouvardos et al., 2009), and the ATDnet system operated by the Met Office.

\section{Lightning detection at the Met Office}

The Met Office has operated its own VLF lightning location network since 1987 (Lee, 1986). The system has developed considerably during its operational life, and the most recent version - ATDnet (Arrival Time Differencing NETwork) was introduced in 2007 (Gaffard et al., 2008).

ATDnet takes advantage of the long propagation paths of the VLF sferics emitted by lightning discharges, which propagate over the horizon via interactions with the ionosphere. ATDnet predominantly detects sferics created by cloud-toground (CG) strokes, as the energy and polarisation of sferics created by CG return strokes mean that they can travel more efficiently in the Earth-ionosphere waveguide, and so are more likely to be detected at longer ranges than typical inter-/intracloud (IC) discharges. The benefit of longer-range relative to higher-frequency networks is obtained with lower 


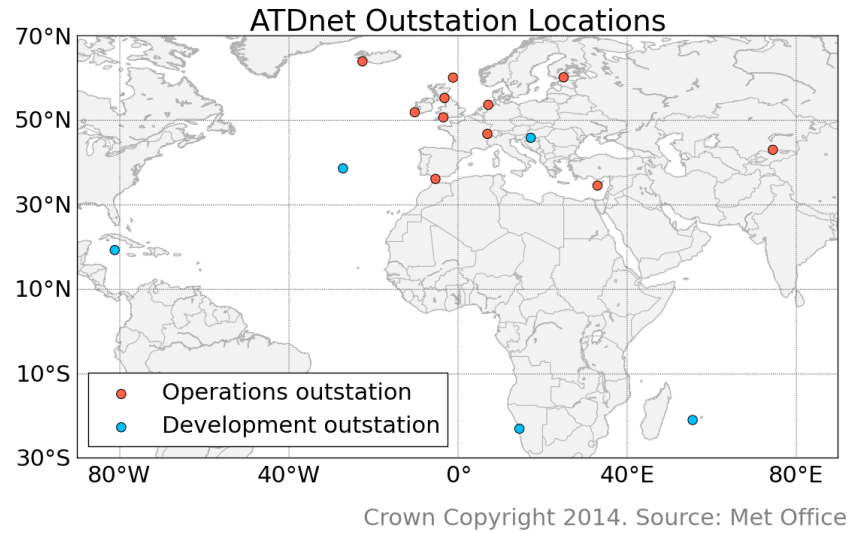

Fig. 1. The locations of ATDnet sensors that contribute to the operations network (red dots), and development outstations (blue dots).

location accuracy: ATDnet location uncertainties within the region enclosed by the network of sensors are of the order of a few kilometres, as opposed to a few hundred metres possible with LF/VHF and VLF/LF systems. The location uncertainty of ATDnet makes it suitable for identifying electrically active cells.

One key advantage of the ATDnet approach, however, is the ability to provide relatively continuous coverage over much of Europe, using only a very limited number of sensors. The ATDnet system consists of 11 sensors (referred to as outstations) that regularly contribute to the "operational network", plus sensors distributed further afield, designated "development outstations". The locations and statuses of these sensors, as of May 2013, are shown in Fig. 1. Coverage extends over regions of open water (e.g. the North Sea, the Mediterranean), where the use of short-range networks is limited by the lack of available sensor sites.

\section{European lightning density}

For continental regions with few large bodies of open water, the use of short-range systems still allows for continuous coverage. This has been used to provide good-quality lightning data across the entire contiguous United States using the National Lightning Detection Network (NLDN) for many years. An interesting use for this data has been to provide continent-wide maps of lightning density, so that annual or monthly characteristics of the distribution of lightning can be analysed, as in Holle et al. (2010).

Due to the more fragmented nature of landmasses within Europe, the use of short-range networks to provide continuous Europe-wide lightning data density maps is less feasible, as European seas would lead to decreased detection efficiency and inhomogeneous coverage that would be difficult to account for. Furthermore, the European regions are covered by a multitude of different national meteorological services, each with their own needs and priorities, making it difficult to create a single, homogenous network covering

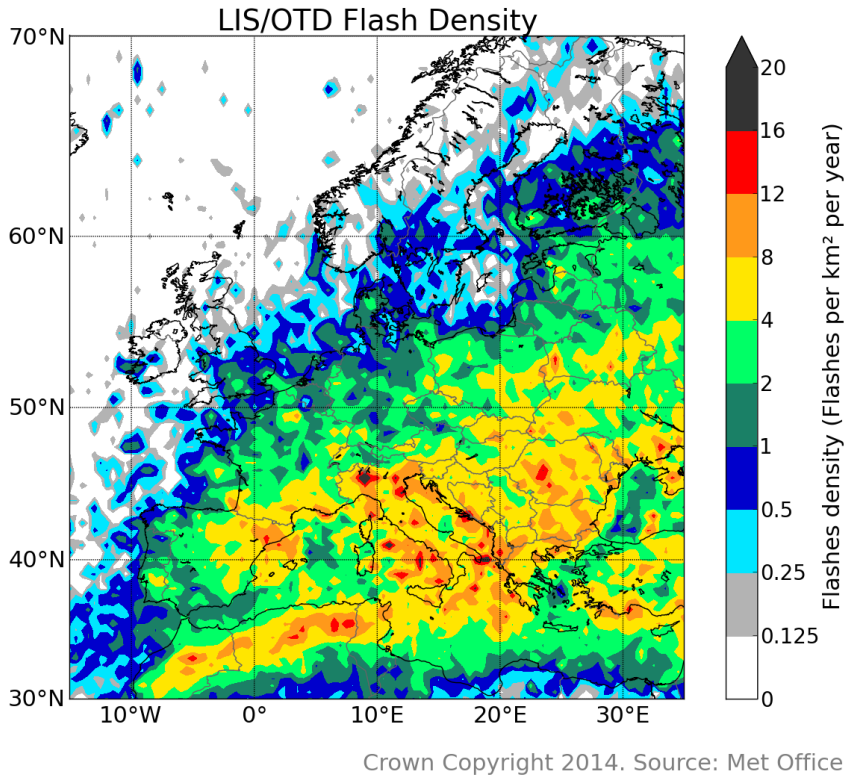

Fig. 2. Estimated European flash density obtained using data from the OTD and LIS satellites.

the whole continent. Assessments of lightning climatology have been carried out at a regional level, however, including analysis covering southern Germany (Finke and Hauf, 1996), Austria (Schulz et al., 2005), Iberia (Soriano et al., 2005), Finland (Mäkelä et al., 2011) and Romania (Antonescu and Burcea, 2010).

Lightning density has previously been measured over the entirety of Europe using the satellite-borne Optical Transient Detector, or OTD (Christian et al., 2003), onboard the Orbview-1/Microlab satellite. This instrument operated between 1995 and 2000, and was the predecessor to the Lightning Imaging Sensor, or LIS (Christian et al., 1999), of the Tropical Rainfall Measuring Mission (TRMM) satellite. One key difference between the two systems was that the OTD's orbit allowed it to detect lightning at higher latitudes: the OTD could detect lightning between $75^{\circ} \mathrm{N}$ and $75^{\circ} \mathrm{S}$ latitude, whereas the LIS can only detect as far north as the southern Mediterranean $\left(38^{\circ} \mathrm{N}\right)$.

The orbital characteristics of the OTD only allowed for observations at any point on the Earth's surface for a few minutes per day. This meant that, by using data obtained over long periods of time, the lightning density could be estimated by assuming that the observed flash rate during a number of satellite overpasses was representative of the average rate for that location. Figure 2 shows the flash density estimation obtained using this technique. The lack of continual observations, and the variable nature of storms, would however mean that the lightning densities estimated from this approach would be unlikely to accurately match the true lightning density. 
This paper aims to provide an analysis of Europe-wide lightning data using relatively continuous coverage provided by the ATDnet system. The approach of Holle et al. (2010) in using data from the NLDN to analyse lightning density in the US for each month in turn was used as a template.

Section 2 describes the approach used in developing the lightning density data for Europe. Section 3 looks at the annual and monthly lightning densities recorded by ATDnet, along with some further analysis of some features of interest. Section 4 analyses some of the statistics of the observed lightning data. Section 5 provides a discussion of the results, and Sect. 6 concludes the study.

\section{Method}

\subsection{ATDnet data}

In order to create plots that represent the average distribution of monthly lightning density as closely as possible, several years' worth of continuous data were required. ATDnet is suitable for this purpose, since it runs as an operational network with very little downtime. Due to modifications to the network when it was re-launched as ATDnet (as opposed to the previous system, simply known as "ATD"), data prior to 2008 were not included. As such, 5 years of lightning data from the period 2008-2012 were used to create the density plots.

Note that occasional sensor or network outages would affect the density data; however, such outages are rare, and the density of ATDnet sensors is high enough to provide some level of redundancy. The length of time from which the data have been taken means that the plots provided in this paper can be used as a useful guide to relative intensities. Further, no adjustment has been made to the data to account for detection efficiency of flashes.

The length of the data period is suitable for smoothing out the effect of individual storms in most regions, particularly during the summer months, when the majority of storms occur. The effects of unusually strong winter storms, or particularly early/late storms in the usual storm season, are still noticeable in some plots. These effects do not detract from the overall usefulness of the plots themselves, but are an interesting effect that will be discussed later. No spatial smoothing (beyond gridding the data) was carried out on the data.

As mentioned in the Introduction, the long-range nature of ATDnet is such that it predominantly detects CG strokes, as the VLF sferics emitted by CG strokes are generally more intense than the sferics emitted by cloud discharges. ATDnet does however detect some more powerful IC discharges, but does not distinguish between IC and CG events. As such, the lightning density plots produced here will be similar to the CG flash distribution of Europe, but the effect of IC discharges in the density could potentially lead to densities in the data presented that are higher than the true CG flash density.
Because of the inability to distinguish between IC and CG discharges, the data presented here can be interpreted as "lightning density", as opposed to "flash density", a term which in the past has been used to specifically refer to CGonly density. It is, however, useful to refer to the fix data correlated together into events using time and space criteria as "flashes", to indicate the fact that these are merged events, despite the fact that this flash data may include IC discharges.

The flash density values obtained would be expected to be lower than the values detected by OTD (Fig. 2). The satellite detector would be expected to have a high IC detection efficiency, while also being capable of detecting CG flashes with sufficient vertical extent that the cloud top would be visibly illuminated.

\subsection{Flash density}

The key component of this study was to process the data from its original format into grids of lightning flash density. The first step was to convert ATDnet "fixes" into "flashes". ATDnet strokes were converted into flashes using the approach derived from that presented by Drüe et al. (2007). Individual fixes were compared against each other using spatial and temporal criteria. Fixes could then be matched together into a single flash if these criteria were met. In this flash correlation algorithm, no maximum inter-stroke separation time was used.

Figure 3 shows the effect of using correlation ranges between 5 and $75 \mathrm{~km}$ between flashes, using a constant maximum flash duration of $1 \mathrm{~s}$. The initial drop in the number of flashes at low ranges would be due to fixes from the same flash being correctly correlated together. At larger ranges, the continuing decrease would be more likely to be caused by incorrect correlations of fixes from discharges that were detected within a second of each other, but were not part of the same flash.

When creating the flash density plots for this study, ATDnet fixes that occurred within $20 \mathrm{~km}$ of and within $1 \mathrm{~s}$ after another fix $(\mathrm{d} t \leq 1 \mathrm{~s}, \mathrm{~d} x \leq 20 \mathrm{~km})$ were grouped together as a single flash. The range criteria used are more relaxed than those used by some other networks, e.g. the US NLDN (Cummins et al., 1998). These criteria should capture the majority of fixes that occur within spatially extensive flashes, or strokes within the same flash where the error on one or more of the strokes were mislocated by a few kilometres. This range should however be less than the separation between storm clouds, meaning that it would be rare that coincident flashes from separate storms would be correlated together by chance. Figure 2 of Drüe et al. (2007) indicates that, although the majority of fixes within a flash are likely to be within $10 \mathrm{~km}$ of each other, sources in excess of $20 \mathrm{~km}$ are still possible from the same flash. Given the $5 \mathrm{~km}$ average location uncertainty of ATDnet at the limits of Europe, these time and space correlation criteria seem justified. 


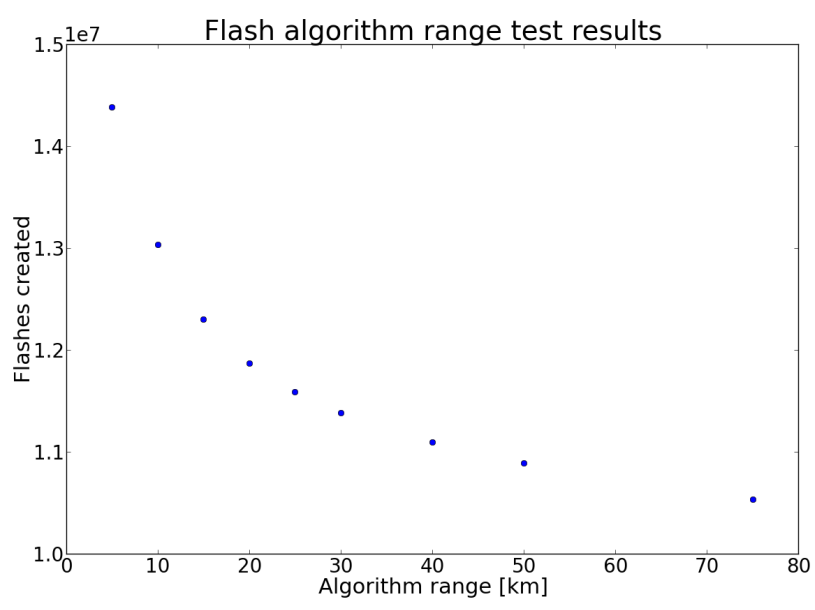

Data from 2012, $\left(30^{\circ} \mathrm{N}-70^{\circ} \mathrm{N}, 15^{\circ} \mathrm{W}-35^{\circ} \mathrm{E}\right)$

Crown Copyright 2014. Source: Met Office

Fig. 3. Flashes created using different correlation ranges for grouping fixes using data from 2012. A maximum flash duration was set at $1 \mathrm{~s}$.

The location and time of the first fix in the group of fixes were used as the location and time of the flash.

Having created a new data set of flashes, density arrays could be created. The density in each point of the array corresponds to the lightning density within a box of set latitude/longitude dimensions. The domain used covers 30$70^{\circ} \mathrm{N}$ and $15^{\circ} \mathrm{W}-35^{\circ} \mathrm{E}$. After some testing, a resolution of 5 boxes per degree of latitude/longitude was chosen. This corresponds to box dimensions of approximately $22 \mathrm{~km} \times 14 \mathrm{~km}$ at $50^{\circ} \mathrm{N}$. This allowed for the resolving of features such as mountain ranges, large valleys and coastal effects, without the plots becoming too "noisy" due to the effects of individual, localised storms. The box size is also much larger than the anticipated location uncertainty of ATDnet within Europe.

Diendorfer (2008) suggests that, in order for measured lightning density to reflect the true lightning density within a grid box to an uncertainty of at most $20 \%$, the number of events per grid box should be 80 or more. Using 5 boxes per degree leads to a box size range of around $419 \mathrm{~km}^{2}$ in the south to $166 \mathrm{~km}^{2}$ in the north. This means that densities in the annual data of greater than approximately 0.1 flashes per $\mathrm{km}^{2}$ per year are likely to be accurate to within $20 \%$.

The numbers of flashes in each box for each month over the 5-year period were counted. This value was then divided by the number of days counted over, and the area of each latitude/longitude box, then multiplied by 365.25 to give consistent units of flashes per $\mathrm{km}^{2}$ per year. Strictly, as the units take the form of events per unit area per unit time, this gives the presented data in units of density rate; to be correct then, the reader should keep in mind that this is average flash density per year.
No correction has been made to the data for spatial variations in the detection efficiency of ATDnet. Although the detection efficiency will vary slightly due to differences in the distance from a stroke to the nearest four ATDnet sensors required to locate a fix, as of yet no model has been created to quantitatively account for this effect. No published, peerreviewed, Europe-wide assessment of ATDnet detection efficiency has yet been made, although assessments of detection efficiency within France using data from a VHF Lightning Mapping Array are in progress. An internal report on the capabilities of ATDnet in Finland (towards the limits of ATDnet detection capabilities in Europe) suggests a diurnally averaged CG flash detection efficiency of $50 \%$, which can be used an an approximate lower limit for ATDnet flash DE across Europe.

A logarithmic scale was used for plotting, as the lightning flash density varies widely across Europe. Some regions, particularly in central Europe and around the Mediterranean, are well known to experience significant numbers of storms each year. On the other hand, the cold seas to the north of the UK experience very little lightning compared with the rest of Europe. The logarithmic scale allowed for lightning data from across the whole of Europe to be visualised in a single plot.

\section{Flash density analysis}

The analysis of the density plots will be divided into sections for the whole year, each calendar month, followed by a closer analysis of some regions of interest.

\subsection{Annual lightning density}

A total of 91656076 fixes were detected by ATDnet across the defined region of Europe from January 2008 to December 2012. Using the flash correlation algorithm, these were grouped into 59061985 flashes, giving an average multiplicity of 1.55 . The average flash densities observed between 1 January 2008 and 31 December 2012 are shown in Fig. 4.

The annual flash densities detected across Europe are generally of the order of $0.1-4$ flashes per $\mathrm{km}^{2}$ per year, a broadly similar range to that observed by Holle et al. (2010) for the northern and western contiguous United States. Peak densities in Europe of less than 8 flashes per $\mathrm{km}^{2}$ per year are less than the peak values observed in Florida (over 14 flashes per $\mathrm{km}^{2}$ per year), however larger sources of heat and moisture, and the physical arrangement of the Florida Peninsula itself, make it particularly susceptible to lightning activity.

Over the UK, Ireland and Scandinavia the densities are generally lower than the rest of Europe. Some of the lowest densities are observed over the Atlantic, North Sea and Baltic Sea. The highest densities occur over mountainous regions of continental central Europe and along the northern coastlines of the Mediterranean. 


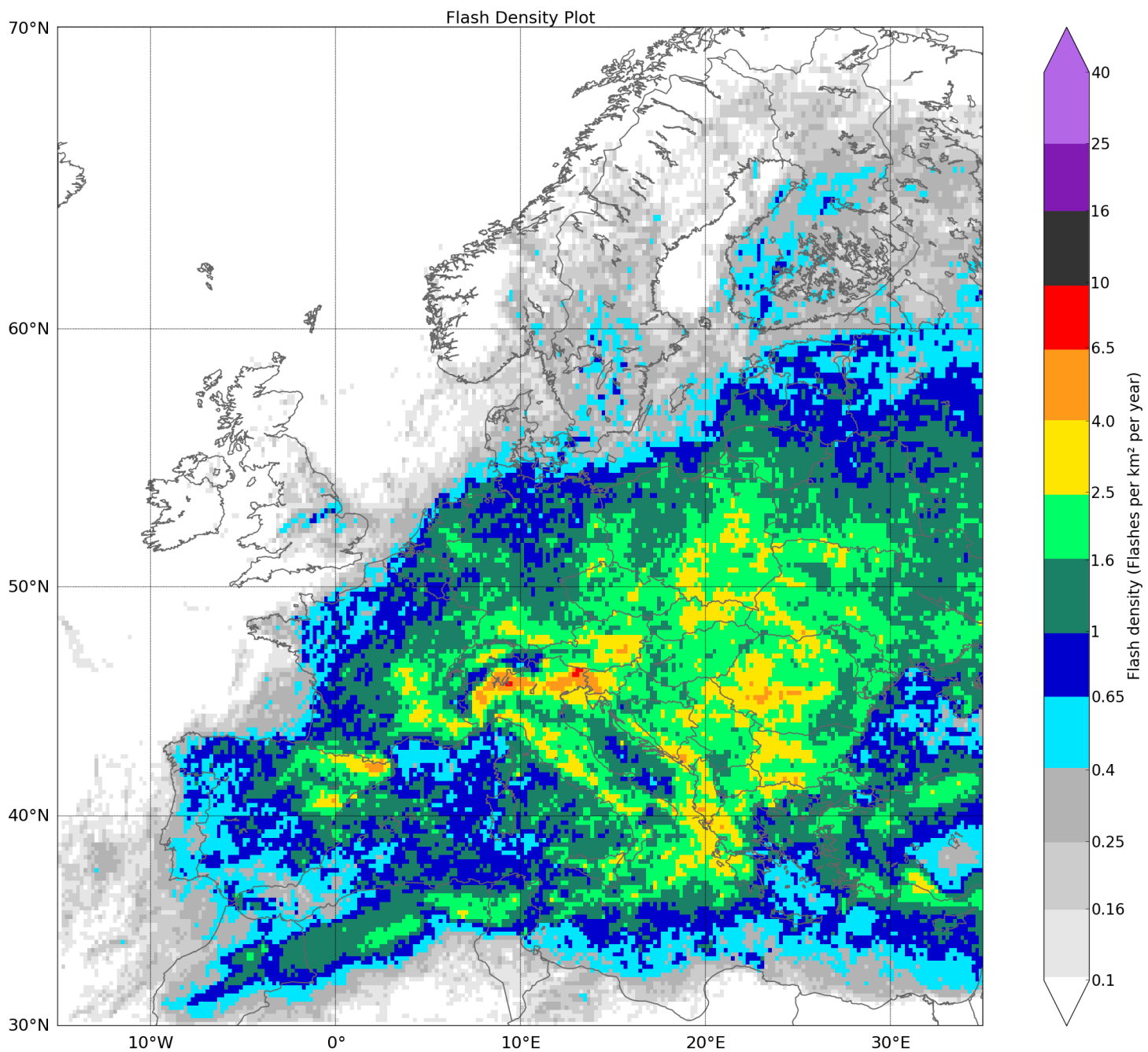

Data from Full Year, 2008 to 2012

Max. density $=7.9$ flashes per $\mathrm{km}^{2}$ per year

Resolution $=0.20^{\circ}$

Crown Copyriqht 2014. Source: Met Office

Fig. 4. Annual detected lightning flash density.

There is a clear preference for higher flash densities over land compared to over open water. The monthly analysis shows that lightning in Europe peaks during the summer months, where land surface heating becomes the main source of the instability that leads to thunderstorms.

The distribution of lightning is similar to that observed by the OTD (Fig. 2). As predicted in the Introduction, the flash densities observed by ATDnet are lower than those observed by OTD (widely greater than 4 flashes per $\mathrm{km}^{2}$ per year), most likely due to the superior IC detection efficiency of the OTD. As ATDnet predominantly detects CG flashes, this is not a comparison of like with like; however, assuming that the distribution of IC and CG events are closely related, this is a good check of the reliability of the ATDnet flash density data set.

\subsection{Analysis by month}

\subsubsection{January}

Lightning occurrence throughout Europe is at a minimum in winter, as displayed in Fig. 5, as the lack of solar heating and available atmospheric water vapour reduce the amount of energy available for storms to develop.

Lightning activity over continental Europe is very low. The regions with the highest lightning activity are around the coastlines of the eastern Mediterranean, along the coasts of Turkey, Greece and the Balkans. Residual heat from the previous summer in the Mediterranean itself provides a source of energy and water vapour for generating convection. 


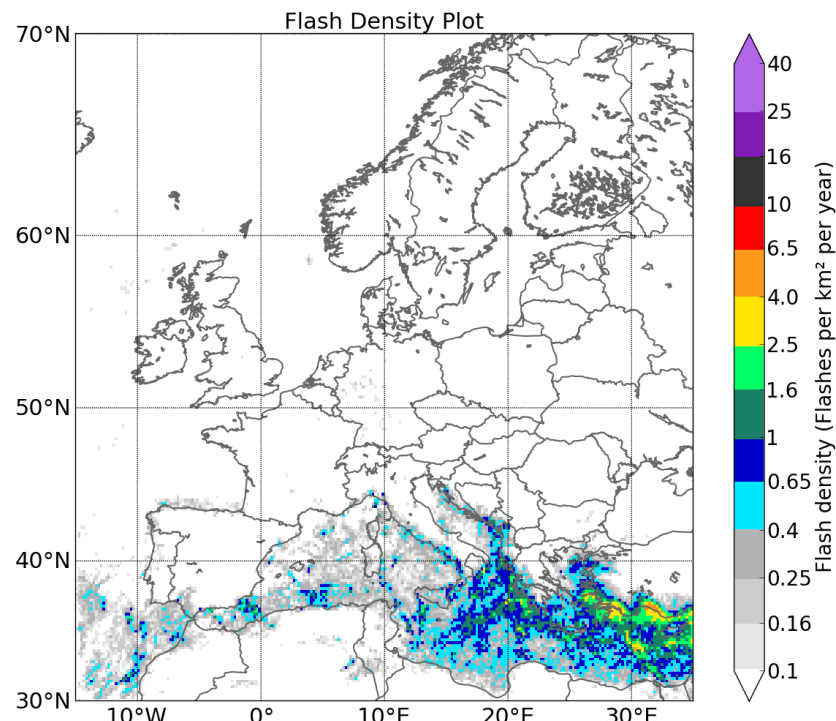

Data from January, 2008 to 2012

Max. density $=6.1$ flashes per $\mathrm{km}^{2}$ per year

Resolution $=0.20^{\circ} \quad$ Crown Copyright 2014. Source: Met Office

Fig. 5. Detected lightning flash density for January.

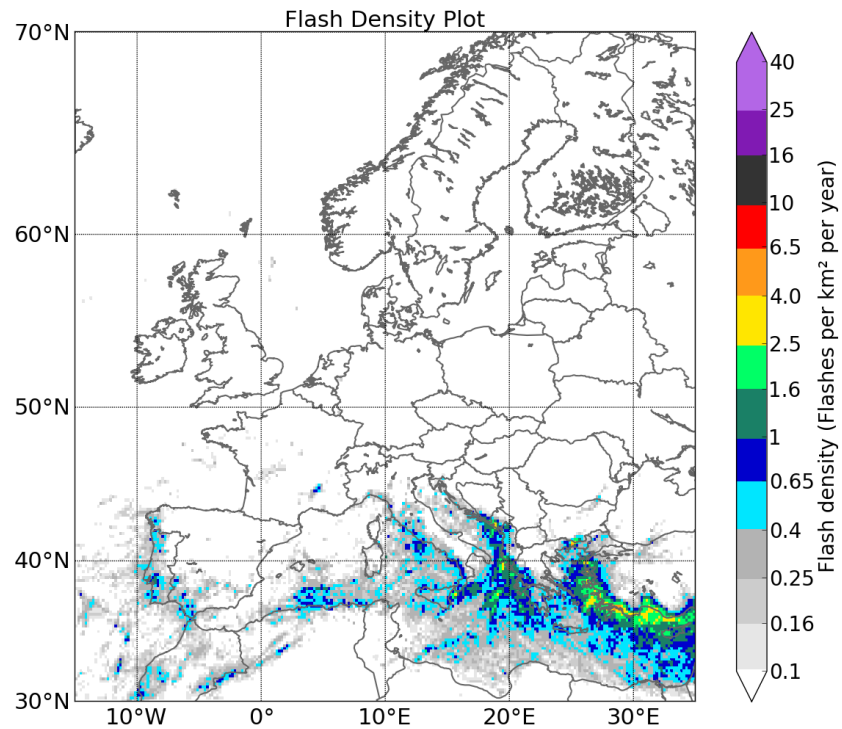

Data from February, 2008 to 2012

Max. density $=5.0$ flashes per $\mathrm{km}^{2}$ per year

Resolution $=0.20^{\circ}$

Crown Copyright 2014. Source: Met Office

Fig. 6. Detected lightning flash density for February.

\subsubsection{February}

The distribution of lightning in February (Fig. 6) is very similar to that of January. The occurrence of lightning in the Mediterranean becomes slightly more concentrated along coastlines relative to January, as the instability is only re-

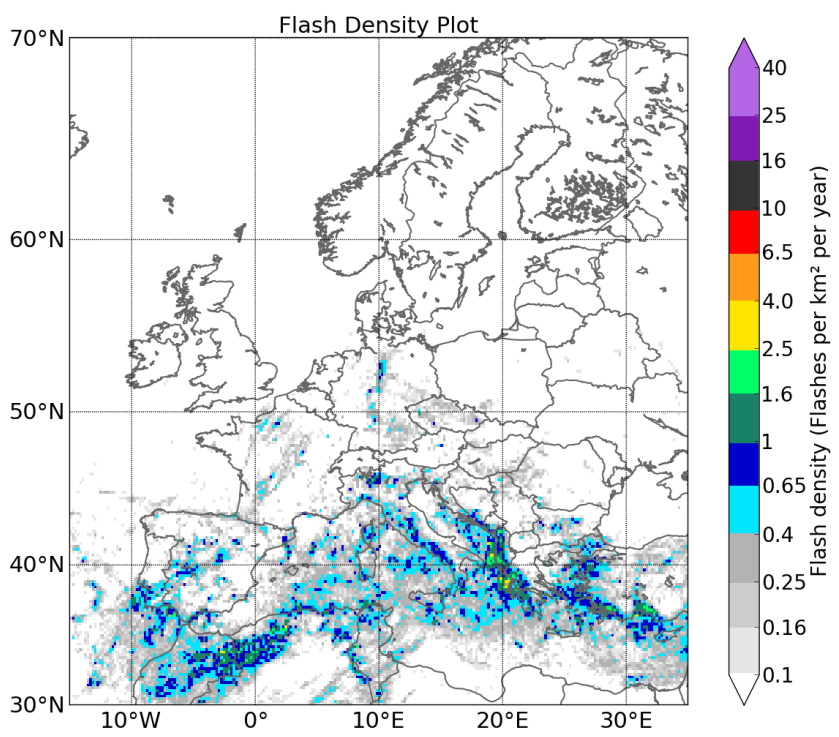

Data from March, 2008 to 2012

Max. density $=4.4$ flashes per $\mathrm{km}^{2}$ per year

Resolution $=0.20^{\circ} \quad$ Crown Copyright 2014. Source: Met Office

Fig. 7. Detected lightning flash density for March.

leased with the additional forcing of coastal convergence and orographic effects.

\subsubsection{March}

March sees the early signs of the resurgence of convection from solar heating (Fig. 7). Coastline lightning density in the Mediterranean is further reduced from February, but activity increases slightly across central Europe. The form of the Atlas Mountains in northern Algeria and Morocco and the Apennine Mountains in Italy are revealed by an increase in lightning density. Northern regions of Europe such as the UK and Scandinavia see little change in lightning between February and March. Despite early signs of increasing activity, the maximum flash density in Europe in March is the lowest of all 12 months.

\subsubsection{April}

The distribution of lightning across Europe takes a noticeable turn between March and April, with the greatest flash densities now occurring over land (Fig. 8). Lightning density over the southern European seas is now reaching a minimum, as residual heat from the previous summer has now been exhausted, and the air begins to warm, reducing instability.

The surrounding land masses, warmed by increasing solar heating, become the main source of convection, as warm land below air that is still relatively cold leads to instability. It is this combination that leads to the generation of "April showers" in the UK, where lightning density has increased compared with March. The regions of the Atlas Mountains, the 

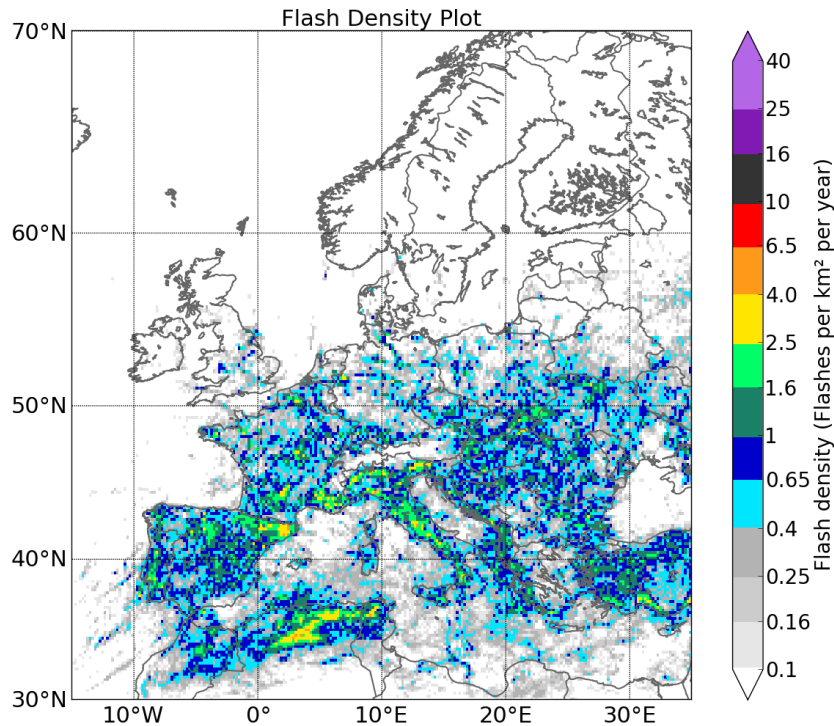

Data from April, 2008 to 2012

Max. density $=5.6$ flashes per $\mathrm{km}^{2}$ per year

Resolution $=0.20^{\circ}$

Crown Copyright 2014. Source: Met Office

Fig. 8. Detected lightning flash density for April.

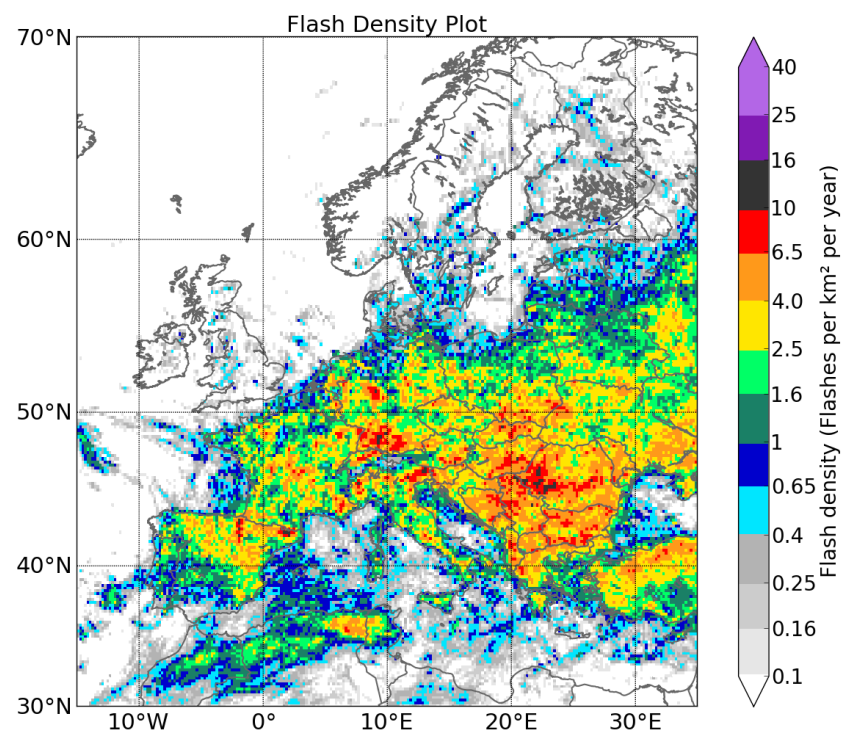

Data from May, 2008 to 2012

Max. density $=14.0$ flashes per $\mathrm{km}^{2}$ per year

Resolution $=0.20^{\circ} \quad$ Crown Copyright 2014. Source: Met Office

Fig. 9. Detected lightning flash density for May.

Italian Apennines, the Pyrenees and the lower slopes of the Alps now show the highest flash densities. The heart of the Alps still show very little lightning activity however, which will be further examined in its own section later.

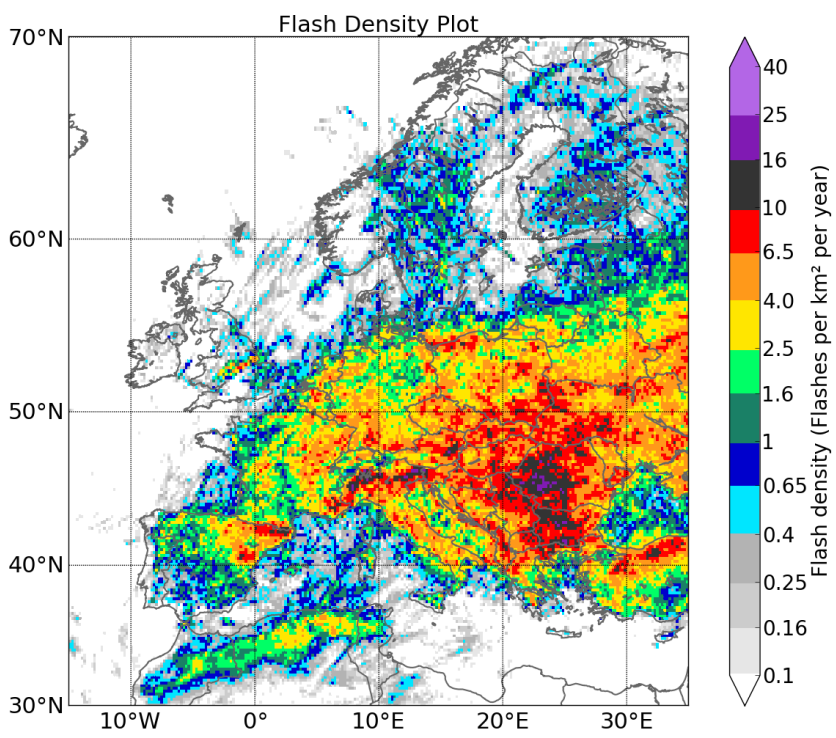

Data from June, 2008 to 2012

Max. density $=23.5$ flashes per $\mathrm{km}^{2}$ per year

Resolution $=0.20^{\circ} \quad$ Crown Copyright 2014. Source: Met Office

Fig. 10. Detected lightning flash density for June.

\subsubsection{May}

The increase in lightning density observed in April continues into May (Fig. 9), with the increase covering almost all of continental Europe. Many regions see lightning activity jump by an order of magnitude.

The first noticeable increases of lightning occur in Scotland, Finland, Norway and Sweden. The central Alps still remain relatively lightning-free, however.

\subsubsection{June}

By June, Romania, Bulgaria and northern Italy demonstrate some of the highest lightning densities in Europe (Fig. 10). Lightning activity along coastlines and over open water is generally low, as the relatively cold water acts as a stabilising influence on the atmosphere.

Individual storm tracks are noticeable in the UK, Sweden and Norway. For example, the noticeable stripe of high lightning density in central England was caused by storms on only one day, on the 28 June 2012. These storms were uncharacteristically intense for the UK, as can be seen by the way they are still easily distinguishable, despite the density plot consisting of 5 years' worth of June data.

\subsubsection{July}

Lightning densities across Europe peak during July (Fig. 11), with the highest density box averaging almost 4 lightning flashes per $\mathrm{km}^{2}$ during the month. The spread of high lightning density generally moves north, with some of the highest 

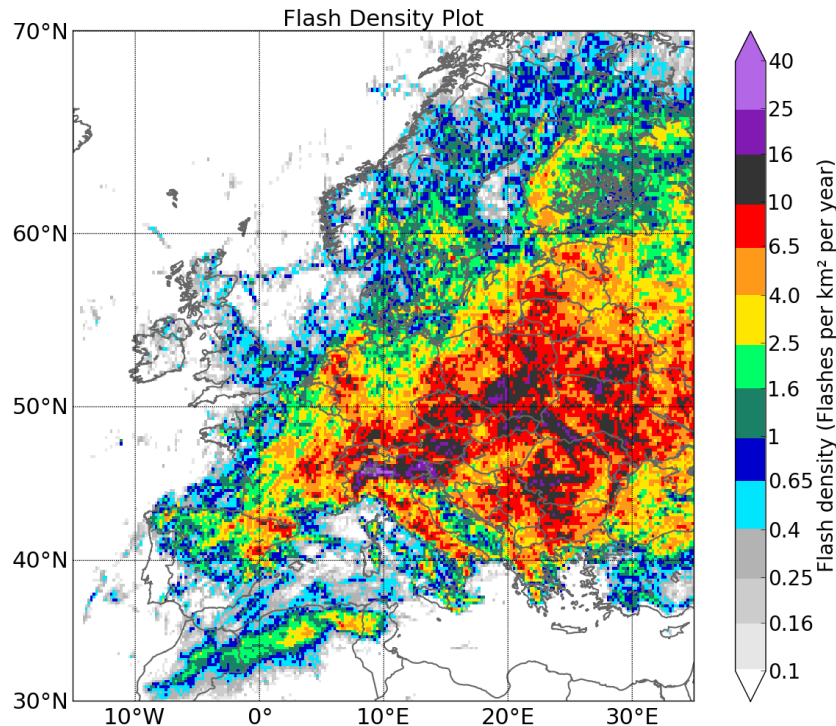

Data from July, 2008 to 2012

Max. density $=42.0$ flashes per $\mathrm{km}^{2}$ per year

Resolution $=0.20^{\circ} \quad$ Crown Copyright 2014. Source: Met Office

Fig. 11. Detected lightning flash density for July.

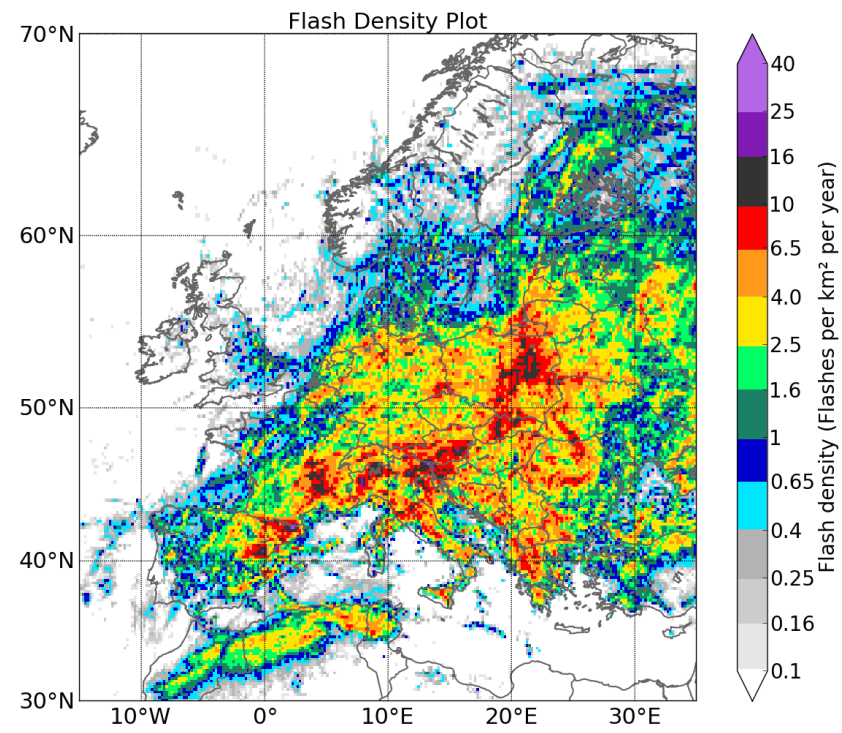

Data from August, 2008 to 2012

Max. density $=30.9$ flashes per $\mathrm{km}^{2}$ per year

Resolution $=0.20^{\circ} \quad$ Crown Copyright 2014. Source: Met Office

Fig. 12. Detected lightning flash density for August.

European lightning densities now observed in Poland and Ukraine.

\subsubsection{August}

Lightning densities begin to drop across continental Europe in August (Fig. 12), as the air temperatures reach their peak

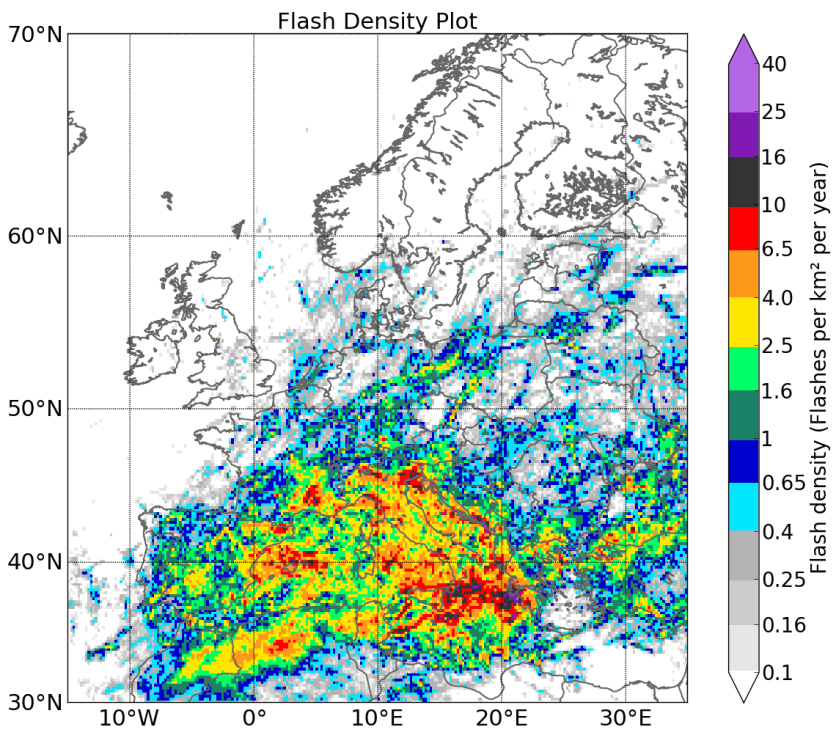

Data from September, 2008 to 2012

Max. density $=26.0$ flashes per $\mathrm{km}^{2}$ per year

Resolution $=0.20^{\circ} \quad$ Crown Copyright 2014. Source: Met Office

Fig. 13. Detected lightning flash density for September.

and solar heating decreases, generating less instability. Lightning activity is still generally restricted to landmasses.

\subsubsection{September}

September sees a dramatic switch in the distribution of European lightning, as can be seen in Fig. 13. Northern Europe sees a sharp drop in observed lightning, whereas the western Mediterranean sees a sharp increase, particularly along coastlines. Cooler air moving over the now warm waters of the Mediterranean leads to the generation of storms. Lightning densities in the eastern Mediterranean remain relatively low, however. Lightning densities are still higher over the Alps, Pyrenees and Atlas Mountains than the surrounding regions. Tracks of individual storms are noticeable across Germany, Poland and the Czech Republic, predominantly from storms in 2011.

\subsubsection{October}

Lightning densities across all land regions become low in October (Fig. 14), as lightning activity over the Mediterranean dominates. Lightning activity in the eastern Mediterranean increases in October, leading to more uniform lightning density between Gibraltar and Cyprus than is observed in September.

\subsubsection{November}

The lightning distribution over Europe in November (Fig. 15) is similar to that of October, but with generally reduced flash densities. The last remnants of notable flash densities over 

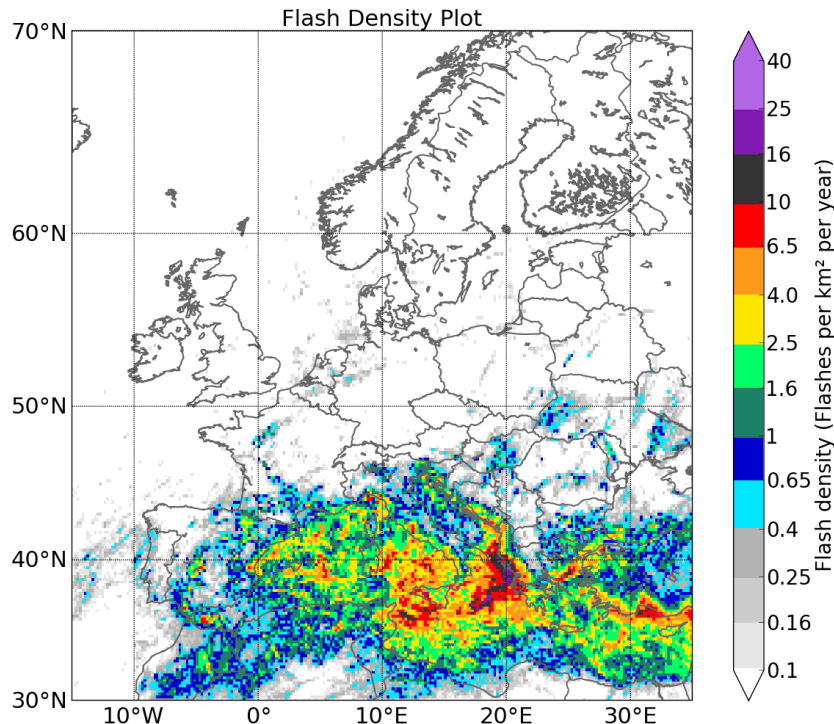

Data from October, 2008 to 2012

Max. density $=22.5$ flashes per $\mathrm{km}^{2}$ per year

Resolution $=0.20^{\circ}$

Crown Copyright 2014. Source: Met Office

Fig. 14. Detected lightning flash density for October.

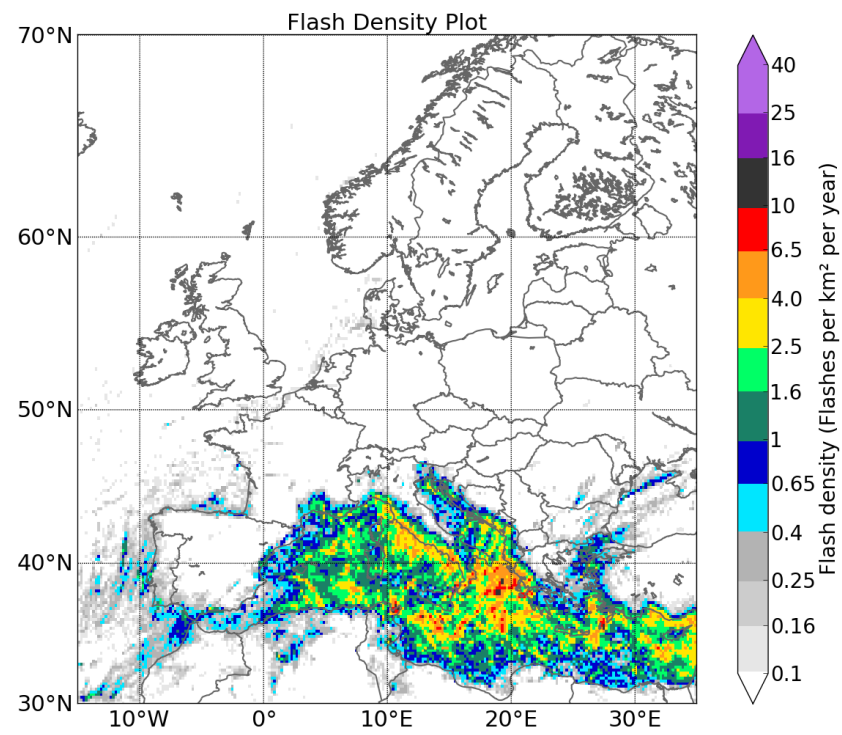

Data from November, 2008 to 2012

Max. density $=20.1$ flashes per $\mathrm{km}^{2}$ per year

Resolution $=0.20^{\circ} \quad$ Crown Copyright 2014. Source: Met Office

Fig. 15. Detected lightning flash density for November.

land in October, such as storms over Spain and the Atlas Mountains, are no longer observed.

\subsubsection{December}

Flash densities in December (Fig. 16) are now returned to the winter pattern observed in January and February. The distribution of the higher flash densities in the Mediterranean now

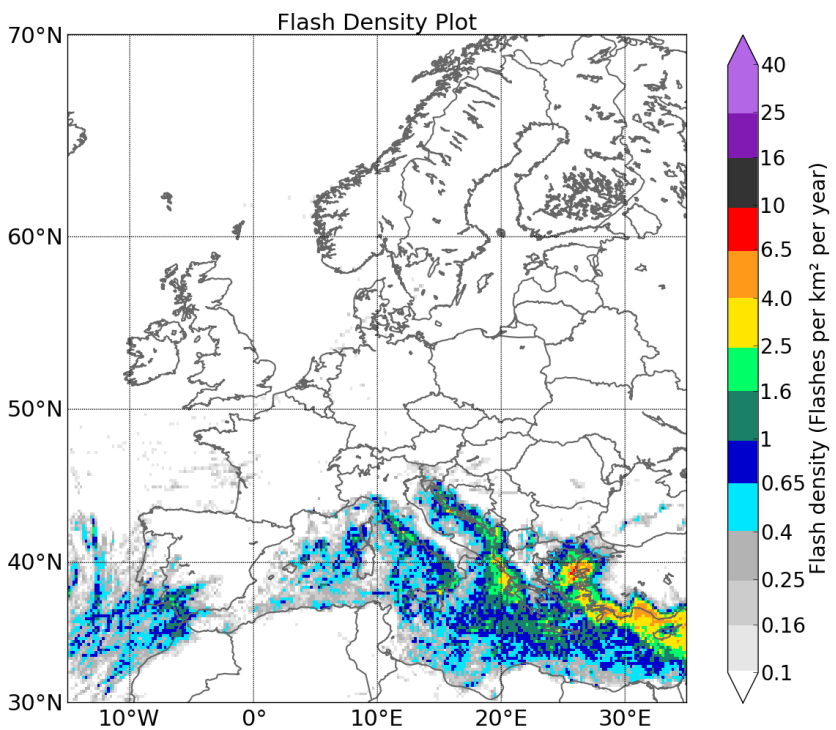

Data from December, 2008 to 2012

Max. density $=9.7$ flashes per $\mathrm{km}^{2}$ per year

Resolution $=0.20^{\circ} \quad$ Crown Copyright 2014. Source: Met Office

Fig. 16. Detected lightning flash density for December.

shift towards the east, with peak densities observed along the coastlines of Greece, Turkey and Cyprus.

\subsubsection{Summary}

The annual pattern of the distribution of lightning across Europe can be summarised as follows. During the winter months at the start of the year, lightning is predominantly restricted to the Mediterranean, where warm waters provide the driver for storm development. In early spring, the land begins to warm, and a switch from mainly sea-based to land-based convection begins in southern parts of the continent. By early summer, the majority of lightning is over land, and land-based convection now extends to the north of Europe. The peak month for European lightning is July. Following a slight decrease in lightning occurrence in August, sea-based convection returns extensively to the western Mediterranean in September. In the remainder of the year, land-based lightning density continues to decrease, and the regions of highest lightning densities in the Mediterranean spread from west to east.

\subsection{Further analysis}

\subsubsection{June 2012 Storms, UK}

On 28 June 2012, unusually severe storms struck the UK, starting in the west of England and the south of Wales in the morning, moving north-eastwards and eventually into the North Sea as the day progressed. The storms generated much 


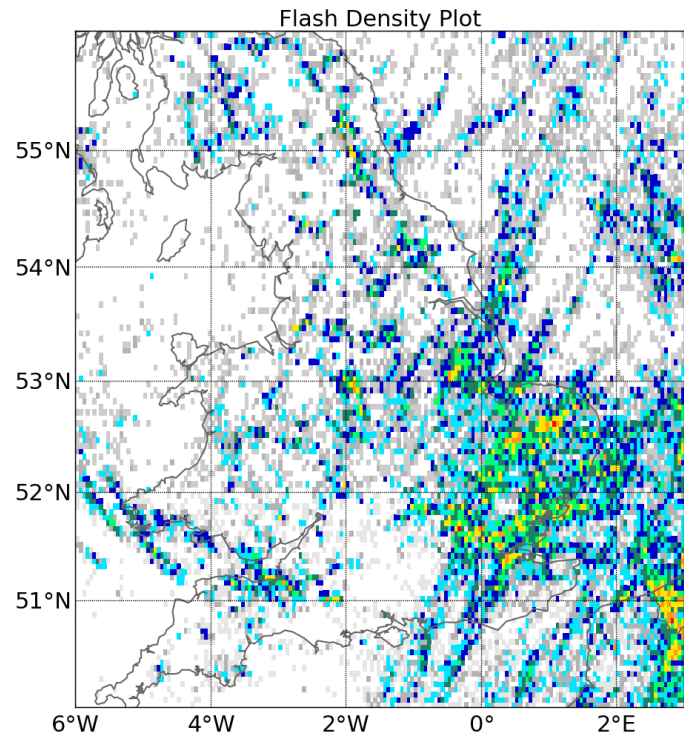

Data from June, 2008 to 2011

Max. density $=7.0$ flashes per $\mathrm{km}^{2}$ per year Resolution $=0.05^{\circ}$

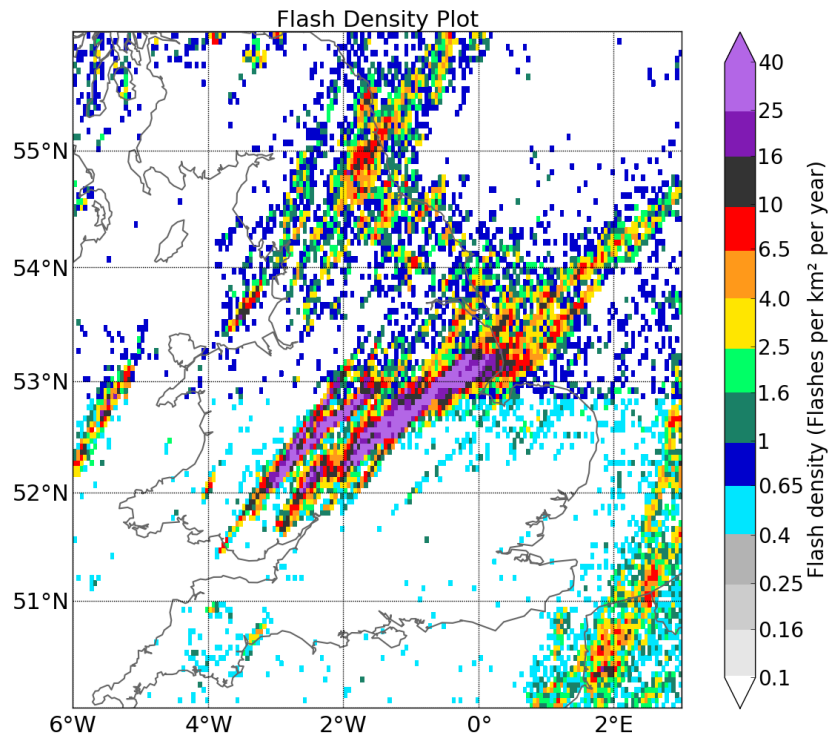

Data from June, 2012

Max. density $=83.1$ flashes per $\mathrm{km}^{2}$ per year

Fig. 17. Detected lightning flash density for June for the UK, between 2008 and 2011 (left), and in 2012 only (right).

media interest, as storms of this level of intensity are rarely observed in the UK.

The lightning density maps using 5 years' worth of data still clearly show the paths of the storms (see Fig. 10), even when the lightning density is averaged from 150 June days. Figure 17 shows the lightning density in June 2012 alongside the density averaged over the previous four Junes, for comparison.

Using extended data sets such as this, measures of return frequencies of such storms could be created and refined over time, providing a useful source for storm risk information.

\subsubsection{Springtime Alps}

As solar heating increases during spring, lightning density increases over much of continental Europe, as warming air near the surface destabilises the relatively cool springtime troposphere. One notable exception to this trend is in the central Alps, where a region of particularly low lightning density (relative to regions at a similar latitude) is apparently collocated with the mountain region; the effect is particularly noticeable in the density map from May in Fig. 18.

The southern slopes of the Alps experience some of the highest flash densities in Europe, where a combination of moisture from the Mediterranean and air being forced up the slopes provides perfect conditions for storms. It is apparent, however, that, once the air has reached the central Alps, the reduction in upward forcing and moisture content leads to a less conducive environment for storm development.

Schulz et al. (2005) noticed the same effect when reviewing 10 years of lightning data from the ALDIS network in
Austria. They attribute this affect to the inner Alpine dry area, where high altitudes lead to a lack of moisture, and high surface albedos from ice/snow reduce the effect of solar heating on the surface, thereby removing two key factors in the generation of thunderstorms.

\subsubsection{Land-sea contrast}

The contrast between lightning densities over the land and sea are relatively diffuse in Fig. 4, where the use of data from the full year shows greater intensities over land than over sea. By looking at the monthly densities, it is possible to distinguish much sharper contrasts between land and sea flash densities near coastlines.

During the summer months along south- and west-facing coasts in the Mediterranean in particular, flash densities can jump by an order of magnitude only a few tens of kilometres inland along stretches of coastline a few hundred kilometres long. This can be seen in Fig. 19, where the flash densities along the coastline of northwest Italy shows a sharp land-sea contrast.

The contrast is not as well defined in winter, but the reversed effect can still be seen around Turkey, Greece, the Balkans and Italy during the winter months, where the flash density is highest over the Mediterranean itself, but decreases rapidly inland from the coasts. 


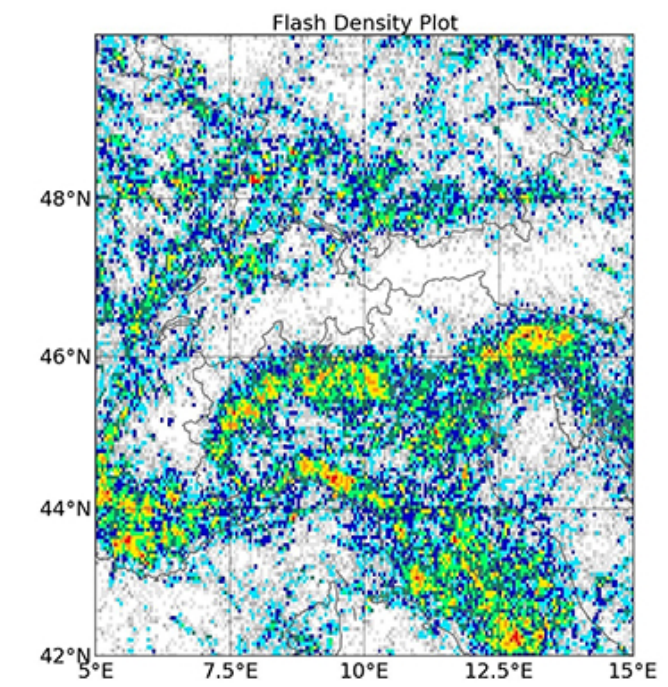

Data from April, 2008 to 2012

Max. density $=10.1$ flashes per $\mathrm{km}^{2}$ per year Resolution $=0.05^{\circ}$

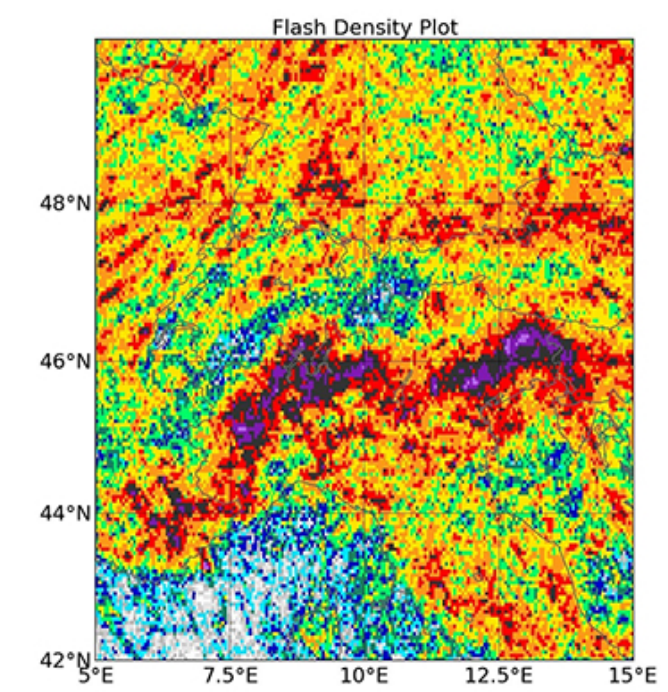

Data from June, 2008 to 2012

Max. density $=44.6$ flashes per $\mathrm{km}^{2}$ per year

Resolution $=0.05^{\circ}$

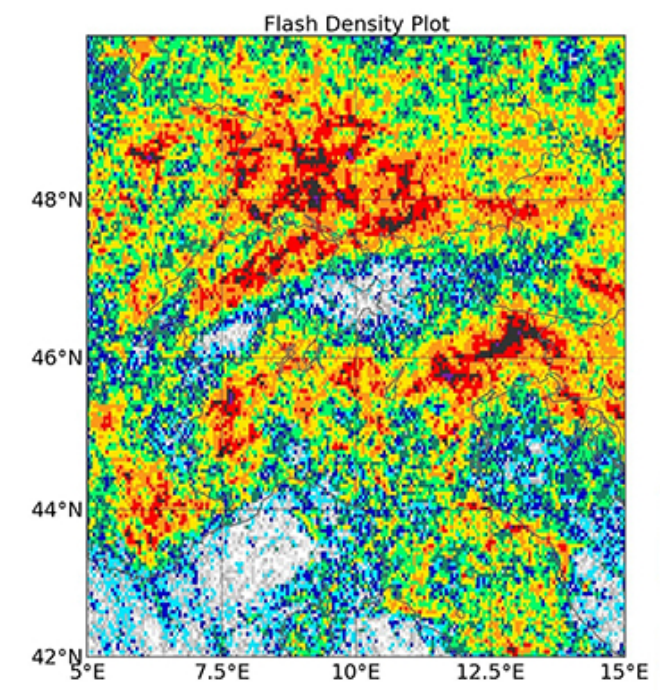

Data from May, 2008 to 2012

Max. density $=21.0$ flashes per $\mathrm{km}^{2}$ per year

Resolution $=0.05^{\circ}$

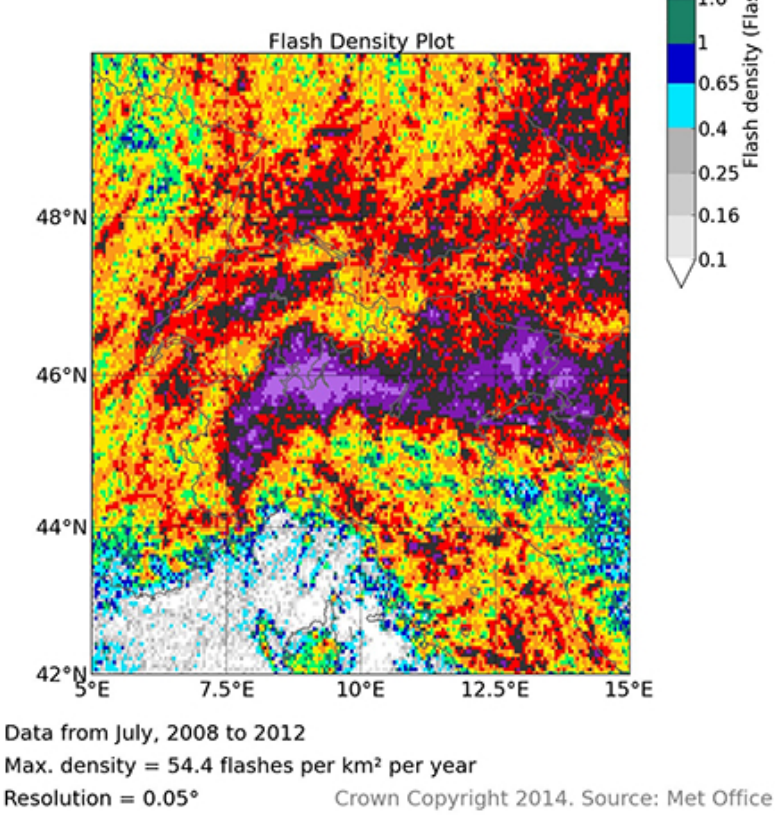

Fig. 18. Detected lightning flash density for the Alps, for April (top left), May (top right), June (bottom left) and July (bottom right).

\section{Flash statistics}

In the following section, seasons are defined as follows: spring consists of March to May, summer consists of June to August, autumn consists of September to November, and winter consists of December to February.

\subsection{Europe-wide average flashes per month}

Figure 20 shows a histogram of the average number of flashes per month detected by ATDnet in Europe between 2008 and 2012. The distribution between April and July shows a rapid rise from the winter minimum to the summer peak. The drop from the summer peak back into the winter low is slower, with a steady decline between July and December.

The peak in the summer months is around an order of magnitude greater than the minimum in the winter months, even with the occurrence of Mediterranean winter storms. Flash rates in July average nearly 100000 flashes per day.

\subsection{Flashes per month in latitude bands}

The histogram of flashes per month in Fig. 20 demonstrates the distribution for all of Europe, but there will inevitably be 


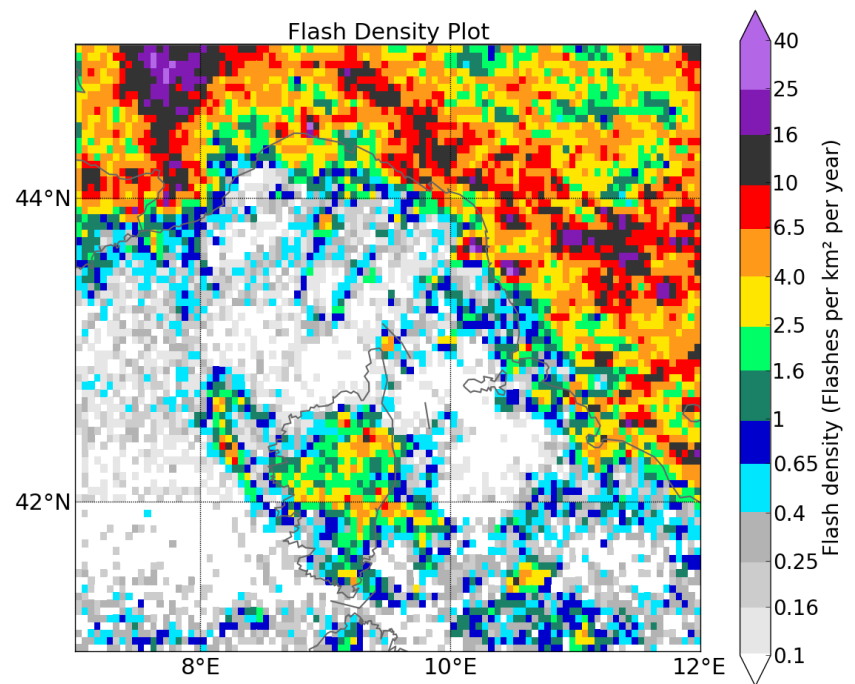

Data from July, 2008 to 2012 Max. density $=29.2$ flashes per $\mathrm{km}^{2}$ per year Resolution $=0.05^{\circ} \quad$ Crown Copyright 2014. Source: Met Office

Fig. 19. Detected lightning flash density for July for Genoa.

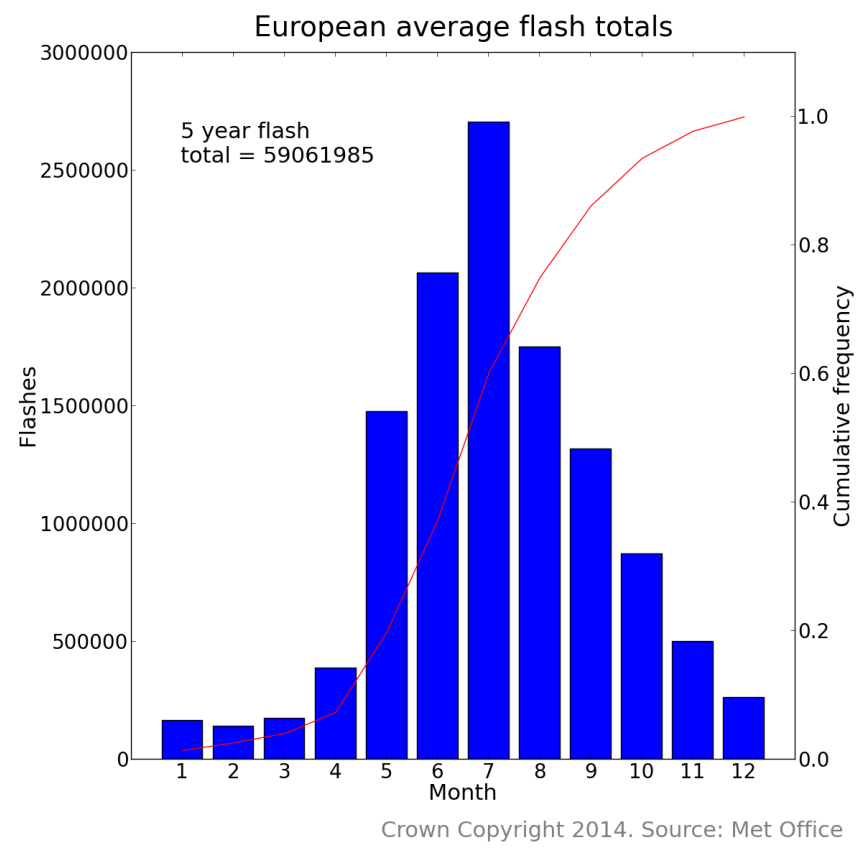

Fig. 20. Monthly average flash detections across all of Europe.

variations within different regions of Europe. It is noticeable in the monthly density plots that increasing flash densities spread northward with time in spring, and that flash densities remain high in the Mediterranean in the winter long after densities have dropped across the continental landmass.

Figure 21 uses the same approach for plotting flashes per month in a histogram, but this time uses four $10^{\circ}$ latitude bands across Europe. This means that features such as early

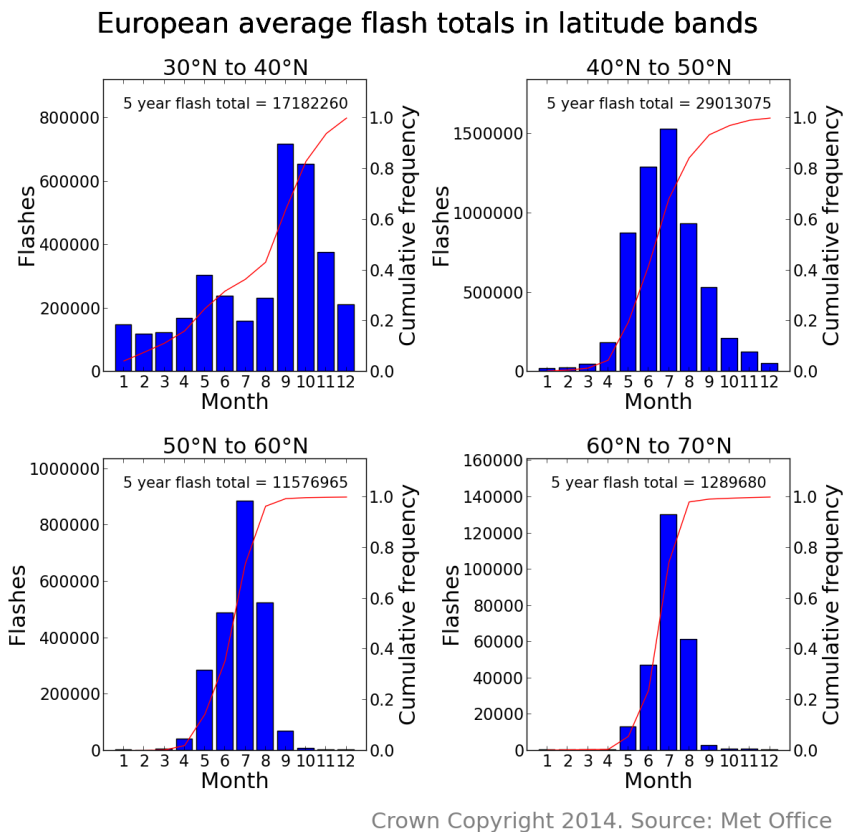

Fig. 21. Monthly average flash detections for latitude bands across Europe, along with the cumulative distribution, for $30-40^{\circ} \mathrm{N}$ (top left), $40-50^{\circ} \mathrm{N}$ (top right), $50-60^{\circ} \mathrm{N}$ (bottom left), and $60-70^{\circ} \mathrm{N}$ (bottom right).

winter storms in the Mediterranean can be distinguished from other regional effects.

The $30-40^{\circ} \mathrm{N}$ latitude band shows a very different pattern to the all-Europe distribution. During winter, spring and summer, average monthly flash totals vary between around 100000 and 300000 flashes, with a slight peak in late spring. During the autumn months, however, the flash totals rise to over 700000 in September and October. This peak can also be seen in the flash density maps for these months (Figs. 13, 14), where flash densities increase sharply compared with the previous month. Conversely, July is a local minimum in the flash rate in this latitude range, whereas July represents a peak in the Europe-wide data and other latitude bands.

The $40-50^{\circ} \mathrm{N}$ band covers much of the landmass of central Europe, and so sees the highest monthly flash averages. The peak in summer is better defined than in the annual data, with much lower relative values (of the order of $1-4 \%$ of the annual total per month) during the winter. The rise in flash rates between April and July, and the gradual drop between August and November, still take a very similar form to the trend seen in Fig. 20, however.

The $50-60^{\circ} \mathrm{N}$ band still shows a peak in average flash totals in July; however the July flash total is only around half that of the $40-50^{\circ} \mathrm{N}$ band. It is also noticeable that monthly average flash totals between October and March are very low. Colder winter air at these higher latitudes provides poor conditions for the generation of thunderstorms. 
Table 1. Statistics of flashes detected in four latitude bands across Europe.

\begin{tabular}{lll} 
Lat. band & Avg. total & Peak month (value, \% of total) \\
\hline $30-40^{\circ} \mathrm{N}$ & 3436452 & Sept $(715886,20.8 \%)$ \\
$40-50^{\circ} \mathrm{N}$ & 5802615 & July $(1528673,26.3 \%)$ \\
$50-60^{\circ} \mathrm{N}$ & 2315394 & July $(885430,38.2 \%)$ \\
$60-70^{\circ} \mathrm{N}$ & 257936 & July $(129896,50.4 \%)$
\end{tabular}

The average flash total for July in the $60-70^{\circ} \mathrm{N}$ band is less than $10 \%$ of the value for the $40-50^{\circ} \mathrm{N}$ band. For the longitude range used, around half of this band is made up of the North Sea, where flash totals are very low all year round. The land masses of Norway, Sweden, Finland and a small part of Russia contribute to the majority of flashes detected in this region. The distribution of flashes at this latitude is even narrower than in the previous band, with a storm season lasting only $3-4$ months in general. Over $50 \%$ of flashes at this latitude occur in July.

These results are summarised in Table 1.

\section{Discussion}

Although the general information presented in this paper may not be of particular surprise to most readers (i.e. that lightning in Europe is most intense over the continent during summer, that higher latitudes experience less lightning than lower latitudes), the ability to analyse the relative intensities of lightning over the European region using continuous and consistent data has not previously been presented.

The ability to carry out seasonal analysis allows for better understanding of processes such as the timing of the mode switch from predominantly land-based to sea-based convection in the autumn. The use of continuous Europe-wide data also means that variations in different regions can be put into a wider context.

The effects of unusually intense storms are visible in most months of data. Had the data from ATDnet been available for a longer period, such effects could be reduced in the flash density analysis. However, data were only used from a period where the performance of ATDnet could be assumed to be relatively homogeneous. Similar analysis could again be carried out in future; in order to repeat the analysis with reduced "noise", however, the key results would still be likely to remain unchanged.

It is desirable that, following the calculations of Diendorfer (2008), the number of events per grid cell should exceed 80 , in order to provide an estimated uncertainty of the density value of $20 \%$ or less. This is achievable for much of Europe in the annual data, except in the very low lightning activity regions in the northwest of Europe. In the monthly analysis, however, lightning densities in excess of 1 flash per $\mathrm{km}^{2}$ are required in the northern limits of the region to achieve this criterion. Care should be taken then in interpreting the monthly data: they are suitable for observing overall trends, but the actual values in individual grid boxes will be subject to a high degree of uncertainty. The grid box dimensions used (i.e. based on latitude/longitude limits) were chosen based on their simplicity to understand; however the effect that the area reduces with increasing latitude, where the lightning density also decreases, is unfortunate. The fact that lightning density varies by orders of magnitude across Europe makes it difficult to select a grid scheme that both shows sufficient detail in high-density regions and also prevents high uncertainties in low-density regions.

Readers should be aware that, while the data provide a good representation of lightning density across Europe, there are still factors in the methodology of the way the data are obtained that will mean they do not exactly represent the true European CG flash density, as is true with any observation system. For example, the design of ATDnet means that it will predominantly detect the emissions from CG return strokes. However, VLF systems have been shown to detect a proportion of IC discharges, as observed in data obtained by the WWLLN (Jacobson et al., 2006). As yet unpublished results obtained by analysing ATDnet data appear to confirm that ATDnet also picks up a proportion of IC discharges, but with a reduced detection efficiency relative to CG flashes. The difference in detection efficiency between IC and CG discharges is thought to predominantly be caused by the fact that CG return strokes are generally more powerful than IC discharges, and so are more easily detected at long ranges. The use of algorithms for discriminating flash type by estimating the arrival time difference between a surface and an elevated source at the estimated flash location are difficult to implement for long-baseline systems like ATDnet, due to the minimal path difference between such theoretical sources at ranges of hundreds to thousands of kilometres, and the fact that waveforms are modified as they propagate, reducing the ability to distinguish discharge types based on waveform characteristics. Alternative methods for discrimination have not yet been assessed.

It should also be noted that the detection efficiency of ATDnet has a diurnal variability, attributed to variations in the ionosphere leading to differences in propagation paths of VLF sky waves between the day and night (Bennett et al., 2011). The difference in path length between the ground wave and successive sky waves leads to bands of reduced sferic signal strength caused by interference between signals with paths differing by $n+1 / 2$ wavelengths, where $\mathrm{n}$ is an integer. The effect is more noticeable at night, due to the height of the ionosphere leading to a greater degree of destructive interference.

Diurnal variation in detection efficiency due to VLF interactions with the ionosphere is not a simple challenge to overcome. Higher densities of sensors would reduce the number of interference band regions; however that would also increase costs. The fact that this is a truly physical effect 
means that simply modifying the processing software cannot fully overcome this issue. However, assuming that this issue is broadly uniform across Europe, and that the majority of thunderstorms take place in Europe during daytime hours, the relative flash densities would still be valid. It is for this reason that no analysis of the diurnal variation in flash rates has been carried out, as the effect of changes in modal detection efficiency could be misinterpreted as diurnal effects in real flash rates.

Variations in detection efficiency are less pronounced when dealing with flashes than would be the case if we were to work with strokes. In regions of high sensor density, a high detection efficiency is achievable for flashes and strokes; at longer ranges, weaker subsequent return strokes will become harder to detect, but the most powerful stroke in the flash may still be detected. Indeed, such an effect can be observed in the data of Orville et al. (2011), where the averaged multiplicity of flashes detected by the North American Lightning Detection Network decreases with increasing distance from the network. Analysis of regional average multiplicity in ATDnet data might reveal such a trend. Little analysis has been made here of flash multiplicity; however it may be of interest to study such effects in future. Care would need to be taken when analysing such a broad region, however, where true regional differences in multiplicity would need to be distinguished from effects of the detection efficiency of subsequent strokes in flashes.

The information presented here may be useful in assessing the initial performance of the MTG-LI after its predicted launch in 2018 (EUMETSAT). Current plans for the device include introducing a lightning density product, but the accuracy of such a product will need to be assessed against what is currently understood of lightning density in Europe.

Other parties that might also be interested in such information would be insurance providers, and also energy and utilities companies, who might be better able to assess risks associated with storms over broad regions. Due to averaging process used in the paper, however, higher-resolution data would be required for risks for specific sites, due to variations in density shorter than the size of a gridbox.

\section{Conclusions}

Lightning density data from across Europe detected using the ATDnet long-range lightning detection system operated by the UK Met Office have been presented. The information provided by the density plots in this paper can be used to gain a greater understanding of the characteristics of lightning across Europe. The continual operation of ATDnet will allow for further refinement in future, which can be used to gain a better understanding of the average seasonal activity of thunderstorms in Europe.
Acknowledgements. The Lightning Imaging Sensor (LIS)/Optical Transient Detector (OTD) science data were obtained from the NASA EOSDIS Global Hydrology Resource Center (GHRC) DAAC, Huntsville, AL (http://thunder.nsstc.nasa.gov/).

Edited by: G. Panegrossi

Reviewed by: two anonymous referees

\section{References}

Antonescu, B. and Burcea, S.: A Cloud-to-Ground Lightning Climatology for Romania, Monthly Weather Rev., 138, 579-591, 2010.

Bennett, A. J., Gaffard, C., Nash, J., Callaghan, G., and Atkinson, N. C.: The Effect of Modal Interference on VLF Long-Range Lightning Location Networks Using the Waveform Correlation Technique, J. Atmos. Oc. Technol., 28, 993-1006, 2011.

Betz, H. D., Schmidt, K., Laroche, P., Blanchet, P., Oettinger, W. P., Defer, E., Dziewit, Z., and Konarski, J.: LINET - an international lightning detection network in Europe, Atmos. Res., 91, 564573, 2009.

Christian, H. J., Blakeslee, R. J., Goodman, S. J., Mach, D. A., Stewart, M. F., Buechler, D. E., Koshak, W. J., Hall, J. M, Boeck, W. L., Driscoll, K. T., and Boccippio, D. J.: The lightning imaging sensor, in: NASA conference publication, NASA, 746-749, 1999.

Christian, H. J., Blakeslee, R. J., Boccippio, D. J., Boeck, W. L., Buechler, D. E., Driscoll, K. T., Goodman, S. J., Hall, J. M., Koshak, W. J., Mach, D. M., and Stewart, M. F.: Global frequency and distribution of lightning as observed from space by the Optical Transient Detector, J. Geophys. Res., 108, ACL-4, $1-15,2003$.

Cummins, K. L., Murphy, M. J., Bardo, E. A., Hiscox, W. L., Pyle, R. B., and Pifer, A. E.: A combined TOA/MDF technology upgrade of the US National Lightning Detection Network, J.f Geophys. Res., 103, 9035-9044, 1998.

Diendorfer, G.: Some comments on the achievable accuracy of local ground flash density values, in: Proceedings of the 29th Conference on the International Conference on Lightning Protection, Uppsala, Sweden, 2008.

Drüe, C., Hauf, T., Finke, U., Keyn, S., and Kreyer, O.: Comparison of a SAFIR lightning detection network in northern Germany to the operational BLIDS network, J. Geophys. Res., 112, D18114, doi:10.1029/2006JD007680, 2007.

Ducrocq, V.: HyMeX-SOP1, the field campaign dedicated to heavy precipitation and flash-flooding in Northwestern Mediterranean, in: EGU General Assembly Conference Abstracts, 15, p. 2539, 2013.

EUMETSAT: Meteosat Third Generation - EUMETSAT, http://www.eumetsat.int/website/home/Satellites/ FutureSatellites/MeteosatThirdGeneration/index.html, access: 08 August 2013.

Finke, U. and Hauf, T.: The Characteristics of Lightning Occurrence in Southern Germany, Institut für Physik der Atmosphäre Oberpfaffenhofen: Report, Inst. für Physik der Atmosphäre, 1996.

Gaffard, C., Nash, J., Atkinson, N., Bennett, A., Callaghan, G., Hibbett, E., Taylor, P., Turp, M., and Schulz, W.: Observing lightning around the globe from the surface, in: the Preprints, 20th Interna- 
tional Lightning Detection Conference, Tucson, Arizona, 21-23, 2008.

Holle, R., Cummins, K., and Demetriades, N.: Monthly distributions of NLDN and GLD360 cloud-to-ground lightning, in: International Lightning Detection Conference, 2010.

Jacobson, A. R., Holzworth, R., Harlin, J., Dowden, R., and Lay, E.: Performance assessment of the world wide lightning location network (WWLLN), using the Los Alamos sferic array (LASA) as ground truth, J. Atmos. Oc. Technol., 23, 1082-1092, 2006.

Lagouvardos, K., Kotroni, V., Betz, H., and Schmidt, K.: A comparison of lightning data provided by ZEUS and LINET networks over Western Europe, Nat. Hazards Earth Syst. Sci., 9, 17131717,2009 http://www.nat-hazards-earth-syst-sci.net/9/1713/2009/.

Lee, A. C.: An operational system for the remote location of lightning flashes using a VLF arrival time difference technique, J. Atmos. Oc. Technol., 3, 630-642, 1986.

Mäkelä, A., Rossi, P., and Schultz, D. M.: The Daily Cloud-toGround Lightning Flash Density in the Contiguous United States and Finland, Monthly Weather Rev., 139, 1323-1337, 2011.
Orville, R. E., Huffines, G. R., Burrows, W. R., and Cummins, K. L.: The North American lightning detection network (NALDN)Analysis of flash data: 2001-09, Monthly Weather Rev., 139, 1305-1322, 2011.

Said, R., Inan, U., and Cummins, K.: Long-range lightning geolocation using a VLF radio atmospheric waveform bank, J. Geophys. Res., 115, D23108, doi:10.1029/2010JD013863, 2010.

Schulz, W. and Diendorfer, G.: EUCLID network performance and data analysis, in: Proceedings of the 17th International Lightning Detection Conference (ILDC), AZ, Tucson, 2002.

Schulz, W., Cummins, K., Diendorfer, G., and Dorninger, M.: Cloud-to-ground lightning in Austria: A 10-year study using data from a lightning location system, J. Geophys. Res., 110, D09101, doi:10.1029/2004JD005332, 2005.

Soriano, L. R., de Pablo, F., and Tomas, C.: Ten-year study of cloudto-ground lightning activity in the Iberian Peninsula, J. Atmos. Solar-Terrest. Phys., 67, 1632-1639, 2005. 